\title{
Informe Andalucía 2008
}

\author{
Juan Antonio Carrillo Donaire \\ Profesor Titular de Derecho Administrativo \\ Universidad de Sevilla
}

\section{RESUMEN:}

Esta crónica forma parte del Informe Comunidades Autónomas que desde 1989 publica el Instituto de Derecho Público de Barcelona con el auspicio de la práctica totalidad de las Comunidades Autónomas, entre ellas la de Andalucía. El objeto del Informe es dar cuenta de los hechos más destacables de la actualidad política, jurídica e institucional de las Comunidades Autónomas sin abandonar la dimensión valorativa y de juicio, tanto en el contexto en que se producen los distintos acontecimientos como en su perspectiva histórica. El ejercicio 2008 que ocupa esta crónica está marcado por las elecciones autonómicas de 9 de marzo y por la apertura de la VIII legislatura del Parlamento andaluz, que esta llamada a ser la legislatura del desarrollo del nuevo Estatuto para Andalucía de 2007.

\section{ABSTRACT:}

This chronicle is a part of the Comunidades Autónomas 2008 Report published since 1989 by the Institute of Public Law with the support of regional governments. The report aims to give an account of the highlights of the political, legal and institutional framework for each Comunidad Autónoma. The year 2008 is marked by the elections of March 9 and the opening of the VIII legislature of the andalusian Parliament, which is called to be the legislature of the development of new Estatuto approved in 2007.

\section{Palabras clave:}

Desarrollo estatutario de la Comunidad Autónoma de Andalucía, actividad política e institucional de la Comunidad Autónoma de Andalucía.

Key words:

Andalusia regional government, institutional activity and legal developing. 


\section{RASGOS GENERALES}

\section{a) Elecciones autonómicas}

En ejercicio de la competencia recogida por el artículo 127.1 del Estatuto de Autonomía, el Presidente de la Junta de Andalucía disolvió el Parlamento y convocó elecciones autonómicas por Decreto 1/2008, de 14 de enero, que fijó el 9 de marzo como día electoral y el 3 de abril como fecha para la sesión constitutiva de la VIII legislatura del Parlamento andaluz. La convocatoria electoral había sido avanzada por el Presidente Chaves a finales de octubre de 2007, con antelación a la decisión que dos meses más tarde tomara el Presidente Rodríguez Zapatero anunciando elecciones generales para el mismo 9 de marzo, provocando así una nueva coincidencia de ambos procesos electorales (sólo dos de las siete convocatorias electorales autonómicas han sido en solitario, las primeras elecciones al Parlamento andaluz de 1982 y las de 1990).

Antes de desgranar los resultados debemos dejar constancia de un cierto deslucimiento de la campaña electoral a raíz del polémico tratamiento de la información electoral en los medios públicos dependientes de la Administración autonómica, que fueron objeto de tres resoluciones de la Junta Electoral de Andalucía, ratificadas por la Junta Electoral Central, en las que se declaraban distintas infracciones del principio de pluralismo político y de neutralidad informativa por parte de la Agencia pública empresarial de la radio y televisión de Andalucía (RTVA).

El resultado electoral está presidido por el holgado triunfo del PSOE en ambas elecciones, que en Andalucía le permitió reeditar la mayoría absoluta de la pasada legislatura y conseguir su sexta victoria electoral consecutiva (tercera de su cabeza de cartel, el Sr. Chaves, frente a su contrincante popular, el Sr. Arenas). Por su parte, el Partido Popular logró el mejor resultado de su historia. Izquierda Unida Los Verdes-Convocatoria por Andalucía se mantuvo y, finalmente, la Coalición Andalucista, que ya había bajado de forma ostensible en las elecciones municipales de 2007, se quedó por primera vez fuera del Parlamento andaluz.

Los votos obtenidos por el PSOE representan el 48,19 por ciento de los emitidos y se traducen en 56 escaños, 5 menos que en 2004, lo que supone superar en uno el número de escaños necesarios -55- para la mayoría absoluta. El PP, con el 38,63 por ciento de los votos, obtuvo 47 escaños, uno más que en 2000, cuando alcanzó sus anteriores mejores resultados en Andalucía. Esta su- 
bida contrasta especialmente con los resultados de 2004, donde se produjo una brusca bajada de esta formación que truncó su progresión haciéndola descender a 37 escaños. IU-CA, con el 7,09 por ciento, obtuvo 6 escaños, los mismos que en 2004 y que en 2000 y, aunque vuelve a disminuir levemente su porcentaje de votos, se consolida en lo que parece ser su suelo electoral en Andalucía; que, a diferencia de lo sucedido en las elecciones al Parlamento Nacional, le permite formar Grupo parlamentario. Pero, sin duda, el dato más impactante de los resultados electorales fue el estrepitoso fracaso de la Coalición Andalucista que, con el 2,78 por ciento de los votos, perdió cuatro puntos y, con ello, los cinco escaños obtenidos por el Partido Andalucista en 2004, colocando a esta formación en la tesitura de mirar prioritariamente a su reconstitución desde el borde del precipicio.

En suma, la alta participación del 73,56 por ciento del censo, poco menos que en los anteriores comicios autonómicos, no mejora esta vez el resultado del PSOE andaluz. Aún así, los socialistas se impusieron en seis de las ocho Provincias andaluzas, mientras que el PP incrementó su número de votos en todas ellas y logró mayoría en dos, Málaga y Almería. La subida de los populares, unida al estancamiento de IU y la desaparición de los andalucistas, da una vuelta de giro más a la ya marcada tendencia bipartidista de la actividad parlamentaria y la vida pública e institucional en Andalucía.

\section{b) Desarrollo del Estatuto}

La ratificación del Estatuto y el cierre inminente de la legislatura impulsaron en el pasado ejercicio la aprobación de un total de 24 leyes, cifra récord en Andalucía, 16 de las cuales vinculaban de forma directa al nuevo Estatuto (9 de ellas se justificaban expresamente en preceptos estatutarios necesitados de desarrollo). En 2008, la convocatoria electoral y la constitución del nuevo Parlamento en época cercana al periodo estival ha provocado un lógico retraso del comienzo real del curso parlamentario que se aprecia en el escaso número de leyes aprobadas, pese a que el Gobierno ha presentado ante el Parlamento andaluz un calendario legislativo de unas 40 leyes de ejecución del Estatuto. Ello no ha impedido, sin embargo, retomar la agenda del desarrollo estatutario en el terreno de la acción del Gobierno, donde el Ejecutivo ha dado continuidad a gran parte de los requerimientos que imprimía el extraordinariamente voluminoso paquete legislativo aprobado en el curso anterior.

En este contexto, no puede dejarse de señalar que el tema de la "deuda histórica" ha vuelto a ocupar un lugar central en el ejercicio. Es este un tema recurrente, abundantemente tratado en anteriores Informes, al que el ultimá- 
tum contenido en la nueva Disposición Adicional Segunda del Estatuto parece espolear como presupuesto financiero para el pleno desarrollo de la tabla de derechos sociales y de las nuevas competencias asumidas. La citada Disposición señala un plazo máximo de 18 meses para que la Comisión Mixta de Transferencias acuerde los criterios, alcance y cuantía para la ejecución del Acuerdo suscrito en febrero de 1996 (en el que se fijó una metodología para la determinación del importe de la deuda y se entregaron 120 millones de euros a cuenta), precisando que la aplicación de ese nuevo y definitivo acuerdo se realizará en un plazo de tres años a partir de la entrada en vigor del Estatuto. El plazo para cuantificar la deuda finalizaba, así, el 20 de septiembre de 2008. Ocho meses antes de cumplirse dicho plazo, el Consejo de Ministros acordó un segundo anticipo por valor de 300 millones de euros que fue abonado en abril, con lo que en la perspectiva del cumplimiento del plazo estatutario, el abono parcial de la deuda ascendía a 420 millones de euros. Pero lo cierto es que ese nuevo anticipo se producía tras la ruptura de negociaciones en el seno de la Comisión Mixta en torno a la cuantía de la deuda, que se escenificó a finales de septiembre al posponerse en seis meses más su fijación, retrasando el plazo al 20 de marzo de 2009, pero manteniendo como improrrogable el de tres años previsto para liquidar la deuda (marzo de 2010). El tema quedó rematado justo antes de que acabara el año en el contexto de una reunión bilateral celebrada entre el Presidente Chaves y el Presidente Rodríguez Zapatero el 21 de diciembre para abordar la reforma de la financiación autonómica, en la que se hizo público un preacuerdo que fijaba la horquilla de la deuda entre un mínimo de 1.148 millones de euros (cifra muy cercana a los 1.140 millones de euros que estimara el Parlamento andaluz en 2003) y un máximo de 1.742 millones de euros.

Con ello quedaba salvado el principal escollo que la Junta de Andalucía anteponía para pactar la modificación del sistema de financiación autonómico puesta en marcha en mayo por el Consejo de Política Fiscal y Financiera. Los pilares de la reforma son conocidos: el incremento del porcentaje de cesión de los tributos parcialmente cedidos, con una participación de hasta el $50 \%$ en el IRPF, IVA e impuestos especiales; la mayor capacidad normativa autonómica sobre los mismos; y la consolidación del peso poblacional como factor principal del reparto. Este último criterio ha sido especialmente celebrado desde Andalucía, cuyo censo de población es el mayor de España (8.202.220 habitantes en enero de 2008). Los grandes objetivos de la reforma se expusieron en el documento de bases presentado en julio por el Gobierno de la Nación ante el Consejo de Política Fiscal y Financiera, y los distintos detalles comenzaron a perfilarse en el curso de las negociaciones que el propio Presidente Rodríguez Zapatero mantuvo a finales de año con sus homólogos de la 
mayoría de las 15 CCAA afectadas. En dichas negociaciones, la posición de Andalucía se mostró proclive a modular el criterio numérico de la población con elementos como la dispersión y el asentamiento geográfico de la misma. Del conjunto de las reivindicaciones del Ejecutivo andaluz destacan otras que también tienen reflejo en el Estatuto y que se ligan a los principios de suficiencia e igualdad, a la creación de fondos específicos o al objetivo de que el grueso de los mismos se dedique a la sanidad, la educación y los servicios sociales, así como otras precisiones del marco estatutario que ya fueron respaldadas por el Pleno del Parlamento andaluz en su sesión plenaria de 26 de junio.

Uno de los temas prioritarios de la agenda legislativa para el desarrollo estatutario es el de la promoción de vivienda pública, recogida como obligación para los poderes públicos en los artículos 25, 37.1, 56, 74, 92 del Estatuto. En este contexto, y el marco de la Ley 13/2005, de 11 de noviembre, de Vivienda Protegida y el Suelo, es de recordar que en diciembre de 2007 se adoptó el llamado "Pacto por la Vivienda", en el que la Junta de Andalucía, la FAMP, los empresarios, los sindicatos UGT y CCOO y 31 entidades financieras suscribieron el compromiso de construir 300.000 viviendas protegidas durante los próximos diez años. En 2008, el Ejecutivo ha adoptado importantes iniciativas para el cumplimiento de los objetivos señalados en dicho Pacto. En primer lugar, se aprobó el Decreto 11/2008, de 22 de enero, que da cobertura normativa a los convenios que la Junta de Andalucía firma con Ayuntamientos y Diputaciones para dotar suelo urbanizable en el que ejecutar vivienda protegida. En segundo lugar, se ha aprobado el Plan Concertado de Vivienda y Suelo 2008-2012 mediante Decreto 395/2008, de 24 de junio, que materializa los objetivos del Pacto por la Vivienda y avanza otros que luego recogió uno de los proyectos estrella de la presente legislatura: el Anteproyecto de Ley sobre vivienda hecho público por el Gobierno andaluz en noviembre de 2008. En este sentido, el Plan es un anticipo parcial de dicha Ley, aunque centrado en la protección de determinados colectivos.

La política exterior figura entre las prioridades del Ejecutivo para el desarrollo del nuevo Estatuto, que dedica a la acción exterior el Capítulo IV del Título IX (arts. 240 a 244). La mayor atención estatutaria que recibe esta cuestión es consecuencia de la jurisprudencia del Tribunal Constitucional que ha respaldado la participación de las Comunidades Autónoma en las relaciones internacionales habilitándolas para integrarse en el ius contrahendi del Estado, para ostentar un ámbito convencional autónomo y un cierto derecho de representación exterior. El refrendo estatutario de estas competencias justifica el engrosamiento de la agenda internacional del ejecutivo andaluz y de las partidas presupuestarias correspondientes, que para 2009 registran un incremen- 
to del 20\%. Entre el Presidente Chaves y el Vicepresidente primero y Consejero de la Presidencia, el Sr. Zarrias, realizaron en 2008 una decena de viajes oficiales a distintos países. Latinoamérica, la zona más visitada, ha sido objeto de atención especial por dos razones principales: la preparación de los actos conmemorativos del bicentenario de la Constitución de 1812, especialmente promocionados en Centroamérica y el caribe; y la previsión contenida en la Ley 55/2007 de Recuperación de la Memoria Histórica de reconocer la nacionalidad española a los descendientes en primer y segundo grado de exiliados españoles, de gran repercusión en los países del cono sur, singularmente en Argentina, donde la aplicación de la medida podía elevar en torno a 100.000 el número de andaluces residentes en aquel país. Otros destinos europeos, del Magreb o Asia se justificaron en finalidades de promoción turística y comercial.

Otro terreno donde el desarrollo estatutario ha cobrado la mayor celeridad es el de los traspasos que se negocian en el seno de la Comisión Mixta de Transferencias Estado-Comunidad Autónoma, que se erigen como presupuesto necesario para el ejercicio de las nuevas competencias. Fruto de esas negociaciones, el 17 de octubre se aprobaron ocho Reales Decretos de traspaso: El R.D. 1668/2008 transfiere bienes patrimoniales adscritos a una gran variedad de servicios traspasados al inicio de la autonomía. Cuatro más, los RR.DD. 1669/2008, 1670/2008, 1672/2008 y 1673/2008, amplían los medios personales y económicos adscritos a organismos y servicios traspasados en la anterior legislatura (Centros hospitalarios y educativos dependientes del Ministerio de Defensa, Instituto Nacional de Empleo y Parques Nacionales de Doñana y Sierra Nevada). Otros dos, los RR.DD. 1667/2008 y 1671/2008, amplían los traspasos sobre recursos y aprovechamientos hidráulicos correspondientes a las cuencas andaluzas vertientes al litoral atlántico (Confederaciones Hidrográficas del Guadalquivir y del Guadiana). Finalmente, el Real Decreto 1666/2008, especialmente importante, transfiere a la Junta de Andalucía los recursos correspondientes a las aguas de la cuenca del Guadalquivir que discurren íntegramente por el territorio andaluz. Posteriormente, el Decreto autonómico 533/2008, de 22 de diciembre, asignó dichos recursos a la Agencia Andaluza del Agua creada por la Ley de acompañamiento a los presupuestos de 2005, que la configuró como la Administración Hidráulica de la Junta de Andalucía adscrita a la Consejería de Medio Ambiente.

\section{c) Medidas frente a la crisis económica}

La crisis económica mundial desatada a raíz de los escándalos financieros de los activos subprime ha marcado más que ningún otro tema la actualidad del 
ejercicio. La información sobre la magnitud de la crisis, latente y casi agazapada durante el primer tercio de 2008, acabó por saltar al primer plano informativo con la virulencia que desprendían las cifras. El protagonismo alcanzado por esta cuestión, que ha acaparado el discurso político y el programa de gobierno, es proporcional a la alarma social que levantan los datos que se fueron conociendo tras el verano y que se proyectan en forma agravada en las previsiones para el próximo ejercicio (la Comisión Europea apunta una nueva bajada del PIB español -de casi tres puntos en 2008- y una subida del paro cercana al 16\%, mientras que el Fondo Monetario Internacional vaticina un crecimiento negativo para toda la zona euro). Datos como el desplome de la bolsa, la pérdida de liquidez del sistema financiero, la parálisis bancaria, el aumento de la morosidad, la multiplicación de los concursos de acreedores, la acumulación de expedientes de regulación de empleo o el preocupante crecimiento del paro apuntan un largo periodo estancamiento económico y de recesión que se intenta paliar mediante un amplio abanico de medidas acordadas en foros internacionales, europeos y nacionales, principalmente destinadas a favorecer la liquidez del sistema financiero y la generación del empleo (que se traducen en un déficit de las cuentas públicas estatales para 2009 cercano al $6 \%$, en clara disonancia con el crecimiento del 1\% que prevén los presupuestos andaluces).

La gravedad de la situación motivó la adopción del primer Decreto-ley andaluz, de 3 de junio, de medidas tributarias y financieras de impulso a la actividad económica (BOJA núm. 112, de 6 de junio). El estreno de la figura, novedosamente recogida en el artículo 110.1 del Estatuto reformado, es de resaltar. Ha de recordarse que la regulación estatutaria del Decreto-ley sigue muy de cerca la redacción del artículo 86.1 de la Constitución, exigiéndose la concurrencia de un presupuesto de hecho habilitante excepcional (la "extraordinaria y urgente necesidad") y vedando la figura en ciertos ámbitos materiales (sin que pueda "afectar a los derechos establecidos en este Estatuto, al régimen electoral, ni a las instituciones de la Junta de Andalucía”, añadiéndose que tampoco pueden aprobarse por Decreto-ley los Presupuestos). Esta regulación contrasta, sin embargo, con la flexible interpretación que el Tribunal Constitucional ha hecho de la expresión "extraordinaria y urgente necesidad" como presupuesto habilitante del Decreto-ley, así como con la rebajada intensidad que el propio Tribunal ha dado al verbo "afectar" como límite objetivo del Decreto-ley. Así, para el ámbito tributario en el que se mueve este primer Decreto-Ley andaluz, el Tribunal Constitucional tiene declarado que la figura no puede alterar el régimen general los tributos ni los elementos esenciales del deber de contribuir (SSTC 182/1997, 137/2003, 108/2004 y 189/2005). 
La primera medida reseñable del Decreto-Ley se refiere al Impuesto sobre Sucesiones y Donaciones, donde se pretende dinamizar la adquisición de viviendas eliminado prácticamente la fiscalidad en caso de donación y aumentando bastante la reducción en la base imponible para las transmisiones de vivienda mortis causa. Es de señalar que estas reformas fiscales habían sido avanzadas por el Presidente Chaves en su discurso de investidura como ejes principales de una Ley tributaria autonómica. En segundo lugar se modifica el sistema de cálculo de la Tasa autonómica que grava el control sanitario en las instalaciones de tratamiento alimentario de carnes para posibilitar mayores deducciones en la cuota. En tercer lugar destaca la concesión de avales para garantizar los valores de renta fija emitidos por los fondos de titulización de activos. Tras la adopción de este Decreto-ley, el Parlamento de Andalucía acordó su convalidación y tramitación como proyecto de Ley por el procedimiento de urgencia en aplicación de lo previsto por el artículo 111 del Estatuto, de lo que resultó la Ley $1 / 2008$, de 27 de noviembre, de medidas tributarias y financieras de impulso a la actividad económica de Andalucía, y de agilización de procedimientos administrativos (BOJA núm. 245, de 11 de diciembre). La Ley incorpora dos nuevas medidas tributarias: una deducción en el IRPF por la afiliación al régimen especial de empleados del hogar y la supresión de la cuota gradual de la modalidad de actos documentados del Impuesto sobre Transmisiones Patrimoniales y Actos Jurídicos Documentados. Las disposiciones finales de la Ley introducen otras medidas adicionales más alejadas de los requerimientos de la situación económica, entre las que debe ser destacada el favorecimiento de la ejecución de los campos de golf "de interés turístico", a los que deja de exigírseles la previa aprobación del plan territorial que los prevea en los términos que exige el Decreto 43/2008, de 12 de febrero, sobre condiciones de implantación y funcionamiento de campos de golf.

El mismo día en que veía la luz el Decreto-ley que acaba de comentarse, el Consejo de Gobierno aprobó un Acuerdo para potenciar la liquidez y la internacionalización de la economía andaluza y fomentar la competencia (BOJA núm. 112, de 6 de junio), que sumaba 1.374 millones de euros a la ayuda proveniente del llamado "Plan español para el estímulo de la economía y el empleo" aprobado por el Gobierno Nacional en el último trimestre del año (Plan E). Asimismo, el Acuerdo autorizaba a la Consejería de Economía y Hacienda a formalizar una operación de préstamo con el Banco Europeo de Inversiones que el 17 de diciembre firmó el propio Presidente de la Junta de Andalucía por un importe de 50 millones de euros destinados a financiar la rehabilitación de barriadas y centros históricos; así como un convenio con el Instituto de Crédito Oficial para facilitar la financiación de proyectos empresa- 
riales con una movilización de más de 100 millones de euros en préstamos a pymes. Estas medidas se completan con una línea de avales a títulos de renta fija emitidos por fondos de titulación de activos para financiación de pymes y de viviendas protegidas.

Uno de efectos más preocupantes de la crisis es la subida de la tasa de desempleo, que en Andalucía alcanzó la cifra de 720.000 parados a finales de año, lo que representa una tasa de desempleo del 18,3\%. Con idea de frenar su aumento, el Gobierno andaluz aprobó un segundo Decreto-ley 2/2008, de 9 de diciembre (BOJA núm. 244, de 10 de diciembre) para poner en marcha un Programa de Transición al Empleo de la Junta de Andalucía (PROTEJA) con el objetivo de desarrollar en el ámbito municipal un programa de obras y un plan formativo de reinserción laboral. El Programa está dotado con $360 \mathrm{mi}$ llones de euros, que se suman a los 1.426 millones de euros que el Fondo Estatal de Inversión Local creado por el Real Decreto-ley 9/2008, de 28 de noviembre, destinó a los municipios andaluces, en lo que fue una de las principales decisiones de aplicación del Plan Europeo de Recuperación Económica aprobado por la Comisión Europea el 26 de noviembre.

Una decisión muy bien recibida, alejada de estas otras de carácter eminentemente financiero, fue la de ampliar el período de rebajas de forma excepcional, adelantando la fecha de inicio al 2 de enero -en plena campaña navideña- (mediante el Decreto 532/2008, de 22 de diciembre), al igual que hicieran otras tres CCAA.

Este conjunto de medidas tuvo el lógico impacto en el endeudamiento autonómico. En este sentido, es de destacar que el Consejo de Política Fiscal y Financiera, en su sesión de 8 de octubre aprobó el Acuerdo 5/2008 que permitió que la Secretaría de Estado de Hacienda y Presupuestos y la Consejería de Economía y Hacienda formalizaran una Adenda al Programa Anual de Endeudamiento de la Comunidad Autónoma para 2008 que incluía un endeudamiento neto, no previsto en el Programa anual ordinario, compatible con un déficit máximo de hasta el 1\% del Producto Interior Bruto regional. El 5 de diciembre, el Consejo de Ministros autorizó a la Comunidad Autónoma a realizar operaciones de endeudamiento hasta un importe de 1.328 millones de euros, tras lo que el Gobierno andaluz acordó la puesta en circulación de Deuda Pública anotada y la concertación de operaciones financieras por dicho importe (Acuerdos de 15 y 23 de diciembre, BOJA núms. 247 y 254 respectivamente).

La ordenación de las partidas de gasto en los presupuestos de Andalucía para 2009, que ascienden a 33.764 millones de euros, también responde en 
parte al agravamiento de la crisis. Singular atención merecen las asignaciones a las Corporaciones Locales, que reivindican desde hace tiempo mayores recursos. La partida destinada a la coordinación financiera con las Corporaciones Locales aumenta el 10,6\% respecto a 2008 y, dentro de la misma, los fondos incondicionados para la nivelación suben un $25 \%$. Asimismo es de destacar el incremento en un 16\% de los fondos destinados al Plan de Cooperación Municipal y la creación de un Fondo Financiero para operaciones de mejora del entorno local. Estos datos contrastan con las partidas destinadas a las empresas públicas del sector público andaluz, que suben casi un $10 \%$ y representan el doble de gasto que la Administración local.

\section{d) Otros asuntos relevantes}

En el segundo semestre del año se fue instalando una atmósfera de gran tensión entre el poder judicial y el ejecutivo que desembocó, a finales de año, en la convocatoria de una huelga judicial para 2009 por parte de las asociaciones profesionales de la Magistratura, que ponían sobre la mesa -al tiempoun conjunto de reivindicaciones.

El llamado "caso Tirado" está en el origen de este pulso institucional, pudiendo decirse que ha sido el gran catalizador del mismo. Resumiendo muy brevemente los hechos se recordará que el 13 de enero de 2008 la pequeña onubense Mari Luz Cortés, de 5 años de edad, desapareció de su domicilio y el 7 de marzo se encontró su cadáver en la ría de Huelva con signos de violencia. Santiago del Valle, presunto autor de los hechos y con antecedentes penales de pederastia, fue detenido a finales del mes de marzo en un pueblo de Granada y confesó el crimen ante el Juez instructor de Huelva. Sobre él había recaído una sentencia condenatoria del juzgado de lo Penal núm. 1 de Sevilla en noviembre de 2002 por abusos sexuales contra su hija menor, confirmada por la Audiencia de Sevilla en diciembre del 2005. El titular del órgano de primera instancia y responsable de la ejecución de la misma, Rafael Tirado, declaró la firmeza de la sentencia de apelación en enero de 2006 y dictó un auto en el que acordó que no procedía suspender la ejecución de la condena. A pesar de ello la ejecución quedo "de facto" suspendida durante más de un año y medio, porque el juzgado no volvió sobre el caso hasta septiembre del 2007, cuando dictó una serie de diligencias que resultaron infructuosas, porque el procesado no vivía ya en la capital andaluza y fue declarado en paradero desconocido. El día siguiente a la detención de del Valle, el Juez emitió orden busca y captura contra el mismo.

A la vista de estas negligencias, el Consejo Judicial del Poder Judicial abrió una investigación que puso de manifiesto que el Juez Tirado delegaba este tipo 
de tareas en la Secretaria del juzgado, que según el Juez había estado de baja un largo periodo durante el que se paralizaron las ejecutorias, lo que fue desmentido por la Consejería de Justicia de la Junta de Andalucía, que confirmó una baja de dicha funcionaria por un tiempo muy inferior al declarado por el Juez. La irregular actuación judicial motivó la apertura de un expediente disciplinario contra el Juez por parte del CGPJ, mientras que el Ministerio de Justicia hizo lo propio respecto de la Secretaria judicial, a la que sancionó con dos años de suspensión de empleo y sueldo. En septiembre, la Comisión Disciplinaria del CGPJ impuso al Juez Tirado una sanción económica de 1500 euros por una falta grave. En la instrucción quedó subrayada la responsabilidad de la Junta de Andalucía y de la Fiscalía, por estar ambas personadas en el proceso contra del Valle y, por tanto, habilitadas para pedir la ejecución de la condena.

La contrariedad con la que el Ejecutivo recibió esta resolución fue grande. El Presidente del Gobierno dijo que buscaría "todos los caminos legales" para aumentar la sanción a Tirado; mientras que el Ministro de Justicia anunciaba una reforma endurecida del régimen disciplinario de los jueces y se lamentaba de forma reiterada del "daño" que creaba la decisión del CGPJ, culminante de una "sucesión de enormes fallos judiciales". Por su parte, la Fiscalía General recurrió la sanción pidiendo tres años de suspensión para el Juez por considerarlo autor de una infracción de "desatención o retraso injustificado y reiterado en la iniciación, tramitación o resolución de procesos y causas" que la LOPJ tipifica como muy grave.

Los jueces decanos de toda España, reunidos en Cádiz el 8 de octubre, emitieron un comunicado aprobado por unanimidad en el que expresaban su "rotundo rechazo a las constantes injerencias de los responsables políticos en las facultades disciplinarias que competen exclusivamente al poder judicial". Poco después, los Secretarios judiciales promovieron un paro laboral de tres horas para el 21 de octubre que fue secundado por los jueces, que manifestaban así su enojo y dejaban servida la polémica.

Otra noticia que ha marcado el curso de la actualidad andaluza ha sido el movimiento objetor contra la asignatura de educación para la ciudadanía, pieza clave de la reforma educativa de la pasada legislatura. El PSOE, impulsor de la reforma, ha defendido la necesidad de la asignatura y ha negado el derecho a la objeción de conciencia en las CCAA en las que cuenta con mayoría parlamentaria; mientras que el PP, contrario a la asignatura -a la que tacha de doctrinaria-, no ha tenido una posición unívoca en las CCAA en las que gobierna: rebajó los contenidos de la materia pero no se puso de acuerdo en el problema de la objeción. 
En Andalucía se han presentado una parte importante de los más de 1.700 recursos contencioso-administrativos tramitados en toda España contra la Administración educativa autonómica responsable de asegurar la impartición de la asignatura. Hasta la fecha, todos los pronunciamientos del Tribunal Superior de Justicia de Andalucía han estimado el derecho a objetar una asignatura en la que, a juicio de dicho Tribunal, aflora una ideología que violenta la moral de algunas personas quebrando su libertad ideológica, por lo que suspende la obligación de asistencia y superación de la asignatura de los objetores. Frente a esta postura destaca la de otros Tribunales de Justicia, singularmente el asturiano, que niega el sesgo ideológico de la asignatura y, por consiguiente, el derecho de objeción de conciencia. El asunto fue recurrido por la Junta de Andalucía ante el Tribunal Supremo, que habría de resolver a principios de 2009, aunque las Asociaciones de padres objetores ya anunciaron que si el fallo no les era favorable recurrirían al Tribunal Constitucional en amparo y, llegado el caso, al TEDH de Estrasburgo.

Uno de los más polémicos episodios de este enfrentamiento fue provocado por la decisión de la Consejería de Educación de la Junta de Andalucía de publicar en el BOJA las resoluciones desestimatorias de casi un centenar de solicitudes de alumnos que querían objetar contra la asignatura, haciendo públicos los nombres y apellidos de los mismos. La fiscalía de Sevilla abrió diligencias en las que apreció una lesión al derecho a la intimidad de los afectados, protegido por la legislación del menor, la de protección civil del honor, la intimidad y la imagen y la legislación de protección de datos, aunque desistió de demandar a la Junta de Andalucía para evitar en los menores el impacto de un proceso judicial que, al cabo, daría mayor publicidad y trascendencia a la circunstancia. La publicación en el BOJA de los nombres de los objetores fue también amonestada por el Defensor del Pueblo Andaluz, lo que motivó que la Consejera de Educación conminara a sus servicios a preservar el nombre de los menores que figuraran como interesados en estos procedimientos.

A mediados de octubre, el Juez de la Audiencia Nacional Baltasar Garzón dictó un auto autorizando la exhumación de 19 fosas comunes, entre ellas la del barranco de Víznar en la que supuestamente se encuentran los restos de Federico García Lorca, a petición de los familiares de las otras dos personas asesinadas junto al poeta. El auto aprecia delitos "de detención ilegal permanente sin dar razón del paradero, en el contexto de crímenes contra la humanidad". La Fiscalía recurrió la decisión por considerar que los hechos prescribieron en 1977 con la aprobación de la Ley de Amnistía, y que en el momento en que se produjeron eran delitos comunes detención ilegal y asesinato. Asimismo la Fiscalía sostuvo que la competencia no correspondía a la Au- 
diencia Nacional sino a los juzgados de los lugares en los que se cometieron los hechos. Frente a ello, el auto judicial funda la competencia de la Audiencia Nacional en que el origen de los hechos es el alzamiento nacional que encajaría en el delito contra altos organismos de la Nación, no prescrito por estar conexo a las desapariciones. El recurso presentado por el Ministerio Público motivó que, a principios de noviembre, el Pleno de la Sala de lo Penal de la Audiencia Nacional acordara paralizar "con carácter cautelarísimo" la exhumación acordada por el Juez Garzón hasta dilucidar si éste es o no competente para investigar los hechos.

Ajena a esta polémica, la familia de Lorca ha mantenido desde el principio una postura contraria a la posible exhumación de la fosa del barranco de Víznar. No obstante, sus herederos acordaron finalmente no ser ellos quienes impidan la exhumación, aunque hicieron patente su temor de "convertir en un circo" un lugar que para ellos debe preservarse para el recuerdo tal y como está.

La posible fusión de las Cajas andaluzas es otro de los asuntos que ha reclamado atención durante el ejercicio. La postura favorable del Gobierno andaluz a la fusión de las cinco Cajas andaluzas se hizo patente durante la campaña electoral, pese a que las principales Cajas negaran conversaciones al respecto y dejaran entrever su posición desfavorable, especialmente clara en el caso de Cajagranada y la cordobesa Cajasur. La desgana del sector desmoralizó al Ejecutivo andaluz y el propio Presidente Chaves pareció arrojar la toalla antes del verano. Sin embargo, la agudización de la crisis económica presentó una coyuntura favorable a la idea de la fusión, retomada por el Gobierno andaluz al creer "más madura" -en palabras de su Presidente- la posibilidad de que pudiera cuajar en esta legislatura la fusión, al menos, de la sevillana Cajasol y la malagueña Unicaja. Sin embargo, el Vicepresidente segundo y Consejero de Economía, Sr. Griñán, afirmó a finales de año que "hasta mayo del 2009 no se va a producir ningún movimiento", aludiendo a la conveniencia de posponer las conversaciones a un momento posterior a la renovación de los órganos de gobierno de Cajasol prevista para esa fecha. También a finales de año, el Presidente Chaves planteó un "gran acuerdo" a la oposición para hacer posible las fusiones que fue rechazado por el PP, mientras que IU-CA se mostraba renuente, condicionando su apoyo a una previa modificación de la Ley de Cajas de 1999.

Finalmente, ha de señalarse que no ha faltado la controversia en torno a temas aireados como escándalos por algunos medios de comunicación, como la designación de asesores y de personal directivo de las Diputaciones, a las 
que la oposición tacha de servir de cobijo para ex-altos cargos del PSOE; el alto coste del contrato de remodelación del palacio del San Telmo de Sevilla, sede de la Presidencia de la Comunidad; o ciertas irregularidades y deficiencias en la aplicación del plan de ayudas y de recolocación de los antiguos empleados de la factoría gaditana de Delphi, de cuyo cierre dimos cuenta en el pasado Informe.

\section{PARLAMENTO}

Con su nueva composición surgida de las elecciones autonómicas, el Parlamento andaluz se constituyó el 3 de abril en sesión plenaria de bajo la presidencia de Dña. Fuensanta Coves Botella, ex-Consejera de Medio Ambiente, quedando compuesta la Mesa por tres Vicepresidencias (una para cada Grupo Parlamentario), tres Secretarías (dos socialistas y una popular) y una vocalía (popular), amen del Letrado Mayor. Seguidamente quedaron repartidas las presidencias de las quince Comisiones permanentes de carácter legislativo y de las siete Comisiones permanentes no legislativas. Los Grupos parlamentarios quedaron definitivamente constituidos el 9 de abril. En el Grupo Socialista, D. Manuel Gracia Navarro continúa como Portavoz y Presidente del Grupo Parlamentario. Dña. Esperanza Oña es la Portavoz popular, aunque la Presidencia del Grupo Parlamentario la ostenta D. Javier Arenas Bocanegra. D. Diego Valderas continúa como Portavoz del Grupo Parlamentario de Izquierda Unida Los Verdes-Convocatoria por Andalucía.

\section{A) Actividad legislativa}

La primera de las tres Leyes aprobadas en el ejercicio resulta de la convalidación parlamentaria y tramitación como Ley del Decreto-ley 1/2008, de 3 de junio, de medidas tributarias y financieras de impulso a la actividad económica de Andalucía. Las otras dos nacen de Proyectos de Ley presentados por el Consejo de Gobierno.

- Ley 1/2008, de 27 de noviembre, de medidas tributarias y financieras de impulso a la actividad económica de Andalucía, y de agilización de procedimientos administrativos (BOJA núm. 245, de 11 de diciembre).

Aprobado el Decreto-ley 1/2008, de 3 de junio, el Consejo de Gobierno lo remitió a la mesa del parlamento y éste acordó, en su sesión plenaria de 25 de junio de 2008, su convalidación y tramitación como proyecto de ley por el procedimiento de urgencia en aplicación de lo previsto por el artículo 111 del 
nuevo Estatuto de Autonomía para Andalucía. La Ley, como quedó dicho, amplia el conjunto de medidas previstas por aquel Decreto-ley.

- Ley 2/2008, de 10 de diciembre, por la que se regula el acceso de los municipios andaluces al régimen de organización de los municipios de gran población (BOJA núm. 255, de 24 de diciembre).

La Ley se dicta en desarrollo de la Ley estatal 57/2003 de Medidas para la Modernización del Gobierno Local con el fin de implementar plenamente la categoría legal de municipio de gran población y, en consecuencia, que los municipios que tengan dicha condición puedan adaptar su régimen organizativo a lo dispuesto en el Título X de la LBRL. La medida se aplicará a los municipios andaluces que sean capitales de provincia y cuya población no supere los 175.000 habitantes, así como a los que tengan más de 75.000 habitantes y presenten especiales circunstancias económicas, sociales, históricas o culturales. También regulará el acceso a esta categoría de los municipios que sean sede de instituciones autonómicas. Por el contrario, se excluyen los de más de 250.000 habitantes y las capitales de provincia con más de 175.000 , ya que el acceso de estas ciudades a la condición legal de municipio de gran población se regula directamente por la legislación estatal.

- Ley 3/2008, de 23 de diciembre, del Presupuesto de la Comunidad Autónoma de Andalucía para 2009 (BOJA núm. 259, de 31 de diciembre).

Proyectos de Ley

- Reguladora de la mediación familiar en la Comunidad Autónoma de Andalucía (11-07-2008)

- Tramitación como proyecto de Ley del Decreto-Ley 2/2008, de 9 de diciembre, del Programa de Transición al Empleo de la Junta de Andalucía (23-12-2008)

Proposiciones de ley

Del Grupo Popular:

- Relativa a modificación de la Ley 1/1986, de 2 de enero, Electoral de Andalucía (06-05-2008)

- Relativa a modificación de la Ley 1/2004, de 17 de diciembre de 2004, de creación del Consejo Audiovisual de Andalucía (06-05-2008) 
- Relativa a participación de las Corporaciones Locales en los ingresos de la Comunidad Autónoma (23-05-2008)

- Sobre el derecho de tiempos máximos de respuesta en listas de espera del sistema sanitario público de Andalucía (28-05-2008)

- Relativa a ejercicio de competencias normativas en el Impuesto de Sucesiones y Donaciones en la Comunidad Autónoma de Andalucía (09-06-2008)

- Relativa a medidas a favor de las víctimas del terrorismo (25-06-2008)

- Relativa a convivencia escolar (16-07-2008)

- Relativa a unidades especiales de seguridad ciudadana en los cuerpos de Policía Local de Andalucía (22-12-2008)

- Relativa a Agencia Andaluza de Evaluación de la Ley de Dependencia (22-12-2008)

Del Grupo Izquierda Unida Los Verdes-Convocatoria por Andalucía:

- Ha presentado tres proposiciones Ley relativas a la reforma del Reglamento del Parlamento de Andalucía (17-04, 16-06 y 10-10-2008)

\section{B) Actividad parlamentaria en general}

\section{Debates generales ante el Pleno}

\section{- Debate de Investidura}

Los días 16 y 17 de abril tuvo lugar el debate de investidura. Como está reglado, el debate comenzó con el discurso del candidato propuesto por el grupo mayoritario, el Sr. Chaves, para su investidura como Presidente de la Junta de Andalucía. El discurso se centró principalmente en desgranar las líneas del desarrollo estatutario, donde el candidato hizo hincapié en los problemas de la Administración Local para los que, junto al acuerdo sobre financiación, solicitó el diálogo y la colaboración de los Grupos de la oposición. Especial importancia cobraron las cuestiones económicas y tributarias y la consabida concertación social como ejes en los que cimentar la recuperación del deterioro económico y el empleo que, a esas alturas del año, ya se empezaba a reconocer desde las filas del Gobierno. También fueron extensamente tra- 
tados temas ambientales, como la lucha contra el cambio climático y la planificación y el desarrollo territorial sostenible. Al hilo de esta última cuestión, el candidato anunció importantes inversiones en infraestructuras de transporte. En materia social, el candidato dijo que la legislatura sería recordada como la de la plena realización del derecho de acceso a la vivienda, lo que destacó junto al desarrollo de la atención a la dependencia y nuevas prestaciones sanitarias. Una gran novedad fue la previsión de una página web de seguimiento de los 97 compromisos que el candidato lanzó en su discurso de investidura para que la ciudadanía pudiera hacer una observancia permanente y actualizada del estado de ejecución de tales compromisos a lo largo de toda la legislatura (www.juntadeandalucia.es/compromisos20082012)

La mañana del 17 de abril se reanudó la sesión con las intervenciones de los portavoces de la oposición. El Sr. Arenas, Presidente del Grupo Popular y portavoz en el debate, dedicó una parte importante de su discurso a airear las magnitudes de la crisis económica y sus incisivas repercusiones en la Comunidad andaluza, subrayando el carácter agotado del proyecto de gobierno y reiterando su intención de liderar un de cambio desde la oposición que en el futuro "permita sacar a Andalucía de la cola del pelotón autonómico". Por su parte, el Sr. Valderas, portavoz de IU-CA dijo no creer que el Gobierno tuviera "margen de movimiento" frente al Gobierno central. Se quejó del tono reiterativo del candidato, que retomaba -a su juicio- propuestas irrealizadas de legislaturas anteriores y expresó el rechazo de su Grupo a un programa que, al igual que el Grupo de oposición mayoritario, tachó de agotado y falto de credibilidad. Es de recordar que hace cuatro años, en la anterior legislatura, el Sr. Chaves fue investido con el único rechazo del Grupo Popular, puesto que tanto Izquierda Unida como el Partido Andalucista optaron por la abstención. Cerró la sesión, por la tarde, el Portavoz socialista Sr. Gracia, que alabó las iniciativas expuestas por el líder de su partido en Andalucía que -en sus palabras- "colmaban y satisfacían" a su Grupo, que igualmente se congratulaba de la apuesta del candidato por el consenso y el diálogo.

La votación final arrojó un resultado favorable a la investidura del Sr. Chaves de 56 votos a favor y 52 en contra, por lo que fue nombrado Presidente de la Junta de Andalucía por su Majestad el Rey por sexta vez consecutiva.

\section{Otros Debates generales}

- Acerca de la política de aguas, 14 de mayo (Grupos Parlamentarios proponentes: socialista, popular y IU-CA). 
- Sobre la reforma de la financiación autonómica y la financiación local, 25 y 26 de junio (Grupos Parlamentarios proponentes: socialista, popular y IU-CA).

- Sobre la crisis económica en Andalucía, 10 y 11 de septiembre (Grupos Parlamentarios proponentes: popular y IU-CA).

- Sobre las repercusiones para Andalucía del Proyecto de Ley de Presupuestos Generales del Estado para 2009, 8 y 9 de octubre (Grupos Parlamentarios proponentes: socialista, popular y IU-CA).

- Sobre el empleo en Andalucía, 10 y 11 de diciembre (Grupos Parlamentarios proponentes: popular y IU-CA).

\section{Proposiciones no de Ley}

Se apuntan los temas principales sobre los que versaron las 125 Proposiciones no de Ley presentadas al Pleno tras la constitución del nuevo Parlamento.

- del Grupo Parlamentario Socialista: medidas económicas; apoyo a la asignatura de Educación para la Ciudadanía y los Derechos Humanos; cambio climático; eficiencia energética en la flota pesquera; ampliación de la cobertura de servicios de banda ancha; jornada laboral de 48 horas y negociación colectiva; modernización de los servicios sociales comunitarios; financiación de las corporaciones locales; aplicación de la Ley de la Memoria Histórica en Andalucía; impulso de las competencias de disciplina urbanística; financiación de la Ley de Dependencia; objetivos de calidad en el servicio de justicia gratuita; medidas sobre el empleo; actuaciones con relación a los precios de productos alimenticios.

- del Grupo Parlamentario Popular: violencia de género; modificación de la Ley de Incompatibilidades de Altos Cargos de la Administración Autonómica; aumento de la inversión educativa por alumno; contenidos de la asignatura de Educación para la Ciudadanía y los Derechos Humanos; medidas por una vivienda digna; acercamiento de la actividad parlamentaria a la población; situación económica de los Ayuntamientos andaluces; impulso de la red ferroviaria; mejora de la atención sanitaria en verano; pluralidad informativa y acceso a la libre información; creación fondo para atender situaciones impago hipotecas y medidas de acceso y mantenimiento de la vivienda; reforma de la PAC; garantía de las políticas sociales; fondo estatal para los ayuntamientos; recorte del gasto público en la organización de la Administración andaluza y altos cargos; relaciones con Ceuta y Melilla; incumplimiento Estatuto de Auto- 
nomía relativo a la cuantificación de la deuda histórica; Agencia Andaluza de Evaluación Ley de Dependencia; creación de la Oficina Andaluza contra el cambio climático; gratuidad de los libros de texto en Educación Infantil y sustitución del sistema de préstamo por el de propiedad; política sostenible y solidaria del agua; fomento de planes locales de empleo; medidas para paliar los daños por catástrofes naturales en la agricultura.

- del Grupo Parlamentario Izquierda Unida Los Verdes-Convocatoria por Andalucía: acceso a viviendas protegidas de personas divorciadas; traspaso de competencias ferroviarias a la Comunidad Autónoma; viviendas vacías; revisión de la política agraria común; situación de los juzgados de paz; declaración de Andalucía como espacio libre de transgénicos; apoyo a los trabajadores del medio rural; Plan Forestal Andaluz; creación del observatorio de sostenibilidad; centros de internamiento de extranjeros y situación de los inmigrantes; crisis del sector ganadero; espacio radioeléctrico en Andalucía; financiación de los ayuntamientos; agilidad para la tramitación de los PGOUs y construcción de vivienda; actuaciones para mejorar la situación del mundo rural; convenio único para el campo; dotación de suelo público; defensa y desarrollo de la universidad pública; universalización de plazas públicas del primer ciclo de educación infantil.

\section{Interpelaciones}

- del Grupo Parlamentario Popular de Andalucía: relativas a política general en materia de política general en materia de agricultura; de empleo; infancia y familia; tesorería y deuda pública; dependencia; aguas; materia presupuestaria; financiación local; suficiencia financiera de los Ayuntamientos; subvenciones a las Corporaciones Locales; industria; justicia; vivienda; política de personal de la Consejería de Salud; medidas gubernamentales para reducir la brecha tecnológica entre Andalucía y su entorno; medidas del Ejecutivo ante la crisis económica; función pública; educación; ejercicio de competencias normativas sobre tributos cedidos; y política de empleo.

- del Grupo Parlamentario Izquierda Unida Los Verdes-Convocatoria por Andalucía: relativas a política I+D+I en Andalucía; financiación local; vivienda; y aplicación de la Ley de dependendencia.

\section{Mociones}

- del Grupo Parlamentario Popular de Andalucía: relativas a política general en materia de agricultura; tesorería y deuda pública; materia presupuestaria; suficiencia financiera de los Ayuntamientos; y en materia de industria. 


\section{Comparecencias ante el Pleno}

Se presentaron 171 solicitudes de comparecencia al Gobierno, la inmensa mayoría de las cuales suscritas por el Grupo popular. 40 de ellas solicitaban la comparecencia del Consejo de Gobierno ante el Pleno de la Cámara y el resto de distintos miembros del Gobierno.

\section{Preguntas al Gobierno}

Desde el inicio de la VIII Legislatura se han presentado 3.888 preguntas escritas al Gobierno; 837 pregustas orales en Comisión y 430 pregustas orales en Pleno.

\section{GOBIERNO}

La primera medida acordada por el Presidente de la Junta de Andalucía tras su nueva investidura fue la designación y reordenación de su Gobierno mediante Decreto 10/2008, de 19 de abril (BOJA núm. 79, de 21 de abril). En este punto, las novedades más importantes son la creación de dos Vicepresidencias, la primera atribuida al titular de la Consejería de Presidencia y la segunda al de Economía (por Decreto 304/2008, de 20 de mayo, se regularon los Gabinetes correspondientes a esos dos nuevos altos cargos) y la reordenación de las Consejerías, en número de quince, lo que supone crear una más respecto de la pasada legislatura por la división de la anterior Consejería de Obras Públicas, Urbanismo y Transporte en dos nuevas Consejerías: de Obras Públicas y Transporte con amplias competencias en materia de infraestructuras, de un lado, y de Vivienda y Ordenación del Territorio de otro, que aglutina ahora la materia urbanística y de ordenación territorial.

Seguidamente se fueron aprobando los nuevos Decretos que regulan la estructura orgánica las distintas Consejerías y la atribución de funciones a sus órganos y centros directivos: Decreto 85/2008, de 22 de abril, de estructura orgánica de la Consejería de la Presidencia (BOJA núm. 83, de 25 de abril); Decreto 116/2008, de 29 de abril, de la Consejería de Economía y Hacienda (BOJA núm. 87, de 2 de mayo); Decreto 117/2008, de 29 de abril, de la Consejería de Innovación, Ciencia y Empresa (BOJA núm. 87, de 2 de mayo); Decreto $118 / 2008$, de 29 de abril, de la Consejería de Empleo y del Servicio Andaluz de Empleo (BOJA núm. 87, de 2 de mayo); Decreto 119/2008, de 29 de abril, de la Consejería de Turismo, Comercio y Deporte (BOJA núm. 87, de 2 de mayo); Decreto 120/2008, de 29 de abril, de la Consejería de Agricultura y 
Pesca (BOJA núm. 87, de 2 de mayo); Decreto 121/2008, de 29 de abril, de la Consejería de Educación (BOJA núm. 87, de 2 de mayo); Decreto 122/2008, de 29 de abril, de la Consejería de Igualdad y Bienestar Social (BOJA núm. 87, de 2 de mayo), modificado puntualmente por el Decreto 523/2008, de 9 de diciembre (BOJA núm. 246, de 12 de diciembre); Decreto 123/2008, de 29 de abril, de la Consejería de Cultura (BOJA núm. 87, de 2 de mayo); Decreto 191/2008, de 6 de mayo, de la Consejería de Gobernación (BOJA núm. 92, de 9 de mayo); Decreto 192/2008, de 6 de mayo, de la Consejería de Obras Públicas y Transportes (BOJA núm. 92, de 9 de mayo); Decreto 193/2008, de 6 de mayo, de la Consejería de Salud y del Servicio Andaluz de Salud (BOJA núm. 92, de 9 de mayo); Decreto 194/2008, de 6 de mayo, de la Consejería de Medio Ambiente (BOJA núm. 92, de 9 de mayo); Decreto 239/2008, de 13 de mayo, de la Consejería de Vivienda y Ordenación del Territorio (BOJA núm. 97, de 16 de mayo); y Decreto 305/2008, de 20 de mayo, de la Consejería de Justicia y Administración Pública (BOJA núm. 102, de 23 de mayo).

Por su parte, el Decreto 389/2008, de 17 de junio (Consejería de la Presidencia), reguló la composición y funciones de las Comisiones Delegadas del Gobierno, sumando dos (una en materia de Innovación y otra para el Cambio Climático y Acción Territorial) a las dos que ya funcionaban en materias de Bienestar Social y Asuntos Económicos; asimismo adscriben a estas Comisiones Delegadas las doce Comisiones interdepartamentales que hasta ahora estaban adscritas a distintas Consejerías.

Ejercicio de las competencias

La acción de gobierno desplegada en el ejercicio ha sido importante. De la cincuentena de disposiciones administrativas generales hay algunas que, por su ámbito o repercusión, merecen comentadas brevemente en este Informe.

En materia de agricultura hay varias disposiciones de interés. En primer lugar destaca el Decreto 7/2008, de 15 de enero, que renueva el distintivo de calidad de los productos provenientes de la llamada "producción agrícola integrada". A medio camino entre la actividad agraria convencional y la ecológica, la producción integrada obtiene alimentos de calidad a través de métodos sostenibles de fertilización, técnicas fitosanitarias, riego y eliminación de residuos. Con 291.000 hectáreas, 222 agrupaciones y 92 operadores individuales, Andalucía es la primera Comunidad Autónoma española en el desarrollo de este sistema productivo, que comenzó a implantarse en 1995 y que, durante los últimos cuatro años, ha duplicado una superficie productora en la que los principales cultivos son el olivar, el algodón, el arroz y la remolacha. Actual- 
mente están en vigor 20 reglamentos donde se recogen los requisitos específicos exigidos para la concesión del distintivo de garantía a otros tantos productos (11 agrícolas, 3 ganaderos y 6 industriales).

En la mejora de la calidad de la producción agrícola también destaca el Decreto 402/2008, de 8 de julio, de regulación de mercados de productos agrarios en zonas de producción y su registro. Se trata de una disposición especialmente demandada por el sector hortofrutícola, cuya finalidad principal es aumentar la calidad de la producción y la transparencia en los precios. Su ámbito afecta a cerca de 200 entidades y asociaciones (lonjas, alhóndigas y cooperativas) dedicadas a la comercialización de productos agroalimentarios y que en áreas como la hortofrutícola almeriense aglutinan más del $40 \%$ de la producción. El Decreto obliga a producir conforme a estándares normalizados y a implantar sistemas de control de calidad, así como de trazabilidad en la comercialización, de modo que estos instrumentos, hasta ahora voluntarios, pasan a ser obligatorios. Otra de sus novedades es la creación, dentro del Registro de Mercados, de una sección para las denominadas "mesas de precios" -inspiradas en las que ya funcionan en el sector porcino-, que son foros constituidos por compradores, vendedores e intermediarios cuyo objetivo es fijar precios orientativos que sirvan de referencia para las contrataciones.

En materia de desarrollo agrícola y rural, el Reglamento 1698/2005 del Consejo, de 20 de septiembre de 2005, del Fondo Europeo Agrícola de Desarrollo Rural (FEADER) define el enfoque Leader como un método sistemático de intervención sobre un ámbito territorial concreto en el que se aplica una "estrategia de desarrollo territorial" en la que el "Grupo de Desarrollo Rural" es el protagonista fundamental de su ejecución. Cada Grupo de Desarrollo Rural, tal y como establece el Reglamento 1698/2005, deberá elaborar una Estrategia de Desarrollo Rural ampliamente participada por los distintos agentes territoriales. En este contexto, el Decreto 506/2008, de 25 de noviembre, regula y convoca el procedimiento de selección de los Grupos de Desarrollo Rural de Andalucía (GDR) que gestionarán los nuevos programas previstos en este ámbito en los próximos cinco años. Con esta norma, la Junta de Andalucía pone en marcha el Plan de Desarrollo Rural 2007-2013, cuyos fondos se destinarán a la ejecución de proyectos de diversificación económica y mejora de los sectores agrarios, del medio ambiente y de la calidad de vida con incidencia en el $90 \%$ del territorio andaluz.

En el sector de industria y de la sostenibilidad energética es de señalar que, durante la última década, Andalucía ha crecido por encima de la media española en las principales variables. Así, en lo que se refiere al Valor Añadido Bru- 
to $(\mathrm{VAB})$, la industria andaluza ha pasado de 7.957 millones de euros (el 8,8 $\%$ del total de la industria española) en 1995 a 15.687 millones en 2006 (el $9,85 \%$ del VAB industrial español). El empleo industrial ha crecido de 210.983 ocupados en 1995 a 262.231 en el 2006, lo que supone un crecimiento del $24,3 \%$ frente $13 \%$ de media nacional. Andalucía también ha ganado terreno en materia de ventas industriales, ocupando los últimos años el segundo lugar entre las CCAA llegando el pasado ejercicio a los 46.868 millones de euros (el 11,2 \% del total nacional). Este es el contexto en el que se aprueba el Plan Andaluz de Desarrollo Industrial (PADI 2008-2013) por Decreto 10/2008, de 22 de enero, que prevé destinar 4.254 millones de euros a la mejora de la capacidad de innovación, internacionalización y diversificación del tejido industrial de la Comunidad Autónoma. En intima conexión con el PADI, no debe pasarse por alto la publicación en el BOJA, en marzo de 2008, del Plan Andaluz de Sostenibilidad Energética (PASENER 2007-2013) de noviembre de 2007. Se trata de un documento importante, pieza esencial de aplicación de la Ley 2/2007, de 27 de marzo, de fomento de las energías renovables. Con una inversión total de 641 millones de euros, el Plan prevé que en 2013 se produzca con fuentes renovables el 31,8\% de la energía eléctrica, equivalente al consumo del $90 \%$ de los hogares andaluces. Asimismo prevé que el 18,3\% del total de energía primaria proceda de fuentes renovables. Respecto al fomento del ahorro y la eficiencia, el plan propone reducir en un $8 \%$ el actual consumo de energía primaria y situar el consumo de biocarburantes en el $8,5 \%$ del consumo total de gasolinas y gasóleos en el sector del transporte (actualmente el 1\%). En esta actividad económica se prevé un ahorro anual de casi 600 kilotoneladas equivalentes de petróleo (Ktep), que es lo que consumen 685.000 vehículos. Se prevé que estas medidas signifiquen la reducción en torno al 20\% de las emisiones de dióxido de carbono (CO2) por unidad de generación y se evitará la emisión de otros 11 millones de toneladas de este contaminante a la atmósfera. En materia de infraestructuras y calidad del suministro eléctrico, el PASENER plantea disminuir en un 33\% el tiempo total de interrupciones del suministro, objetivo prioritario tras los graves incidentes de 2004.

Junto a este Plan ha de tenerse en cuenta el Decreto 50/2008, de 19 de febrero, que desarrolla la Ley de Fomento de las Energías Renovables y del Ahorro y Eficiencia Energética de 2007 a fin de unificar y agilizar los distintos procedimientos administrativos aplicables a las instalaciones de energía solar fotovoltaica. Andalucía está experimentado un importante crecimiento en la generación de electricidad mediante este tipo de instalaciones. La comunidad ha pasado de contar con una potencia fotovoltaica instalada de 15,4 MW a finales de 2006 a los más de 46,5 MW en instalaciones conectadas a la red eléc- 
trica a principios de 2008, a los que habrá que ir sumando los 416,3 MW que cuentan con autorización para ser instaladas y conectarse a la red. Junto a este tipo de instalaciones existen otras no conectadas a la red que generan un total de $6.231 \mathrm{KW}$ para viviendas de difícil acceso, para las líneas eléctricas convencionales o para pequeños sistemas de bombeo de agua.

En el ámbito de las infraestructuras y obras públicas sobresale el Plan de Infraestructuras para la Sostenibilidad del Transporte en Andalucía (PISTA 2007-2013), aprobado por el Decreto 457/2998, de 16 de septiembre. El Plan, que toma el relevo del Plan Director de Infraestructuras de Andalucía 1997-2007, se convierte en la principal referencia planificadora en materia de de infraestructuras del transporte para los próximos 5 años, en los que pretenden conseguirse cinco grandes objetivos. El primero es favorecer en el transporte el uso racional y sostenible de los recursos naturales y disminuir la emisión de gases de efecto invernadero. Un segundo objetivo es mejorar la eficiencia económica y energética del transporte como elemento clave para la organización y funcionamiento de las actividades productivas. El tercero es intervenir de forma diferenciada en las ciudades y pueblos de las áreas rurales, en las ciudades medias, y en las aglomeraciones urbanas formadas por el entorno de las capitales provinciales y el Campo de Gibraltar. El cuarto es impulsar las infraestructuras del transporte y favorecer el uso del transporte público. Por último, el quinto objetivo, es mejorar la articulación y la cohesión territorial.

Las propuestas relativas a la red ferroviaria se dirigen a garantizar las conexiones exteriores de altas prestaciones de las capitales andaluzas con el resto de la Península, así como las conexiones transversales dentro del territorio andaluz. El objetivo es que en 2013 todas las capitales estén unidas por estos servicios ferroviarios. Respecto a la red viaria, el Plan incluye nuevas conexiones exteriores de gran capacidad y autovías interiores, comprendiendo un total 3.000 kilómetros. La mejora del sistema aeroportuario, integrado por seis aeropuertos que transportaron más de 22 millones de pasajeros en 2007, es otro de los objetivos, que se complementa con un plan de enlaces entre aeropuertos mediante trenes de alta velocidad. En el capítulo de movilidad en áreas metropolitanas, el Plan refuerza y amplia los Consorcios de Transporte en todas las Provincias, además de impulsar nuevas infraestructuras como los metros de Sevilla, Granada y Málaga. En el transporte de mercancías se proyecta el desarrollo de la Red de Áreas Logísticas de Andalucía, formada por los nodos portuarios de Bahía de Algeciras, Huelva, Bahía de Cádiz, Málaga, Sevilla, Almería y Motril, y por los nodos interiores de Jaén, Córdoba, Granada y Área Central de Andalucía, y que conllevará la construcción de centros de trans- 
porte y zonas de actividades logísticas de interés autonómico, cuya superficie total se incrementará en 1.000 hectáreas. Por último, se prevé alcanzar en 2015 los 25.000 puntos de atraque en los puertos deportivos andaluces mediante obras de ampliación de los ya existentes y la creación de nuevas infraestructuras de acuerdo con lo que prevea la ordenación territorial.

En materia de vivienda destacábamos en los rasgos generales de este Informe la aprobación del Decreto 395/2008, de 24 de junio, que aprueba el Plan Concertado de Vivienda y Suelo 2008-2012. El Plan prevé la construcción de 132.000 viviendas protegidas y la rehabilitación de otros 135.378 a fin de alcanzar el objetivo de que cuatro de cada diez viviendas construidas en Andalucía tengan algún tipo de protección al final de la presente legislatura. El Plan se orienta a tres grandes objetivos: promover el acceso a la vivienda protegida en régimen de compra y alquiler, asegurar la dotación de suelo urbanizado para ello y avanzar en la rehabilitación del parque residencial. Dentro del primer objetivo, el Plan Concertado contiene medidas para fomentar el acceso a la propiedad diferenciando los destinatarios de las mismas por su nivel de ingresos y estableciendo tramos de ingresos para cada programa. Igualmente recoge programas de acceso en régimen de arrendamiento y para fomentar el arrendamiento del parque residencial desocupado. En líneas generales se prevén ayudas económicas para que el esfuerzo económico de las personas que acceden a cualquiera de los programas no supere un tercio de sus ingresos en caso de compra y del $25 \%$ en supuestos de alquiler; aunque también se contemplan ayudas para familias con especiales dificultades sociales o en riesgo de exclusión social. La segunda línea que establece este Plan es la rehabilitación del parque residencial existente y mejora de habitabilidad en infraviviendas. Las actuaciones de rehabilitación integral de ámbitos urbanos podrán realizarse a iniciativa de la Administración de la Junta de Andalucía, a través de la Empresa Pública de Suelo de Andalucía, o por iniciativa de los respectivos Ayuntamientos donde se ubique dicho ámbito urbano. La tercera línea son medidas para la urbanización de suelo con destino a la promoción de viviendas protegidas y para la obtención de suelo a urbanizar para su incorporación a los patrimonios municipales y al Patrimonio Autonómico de Suelo. El Plan fomenta la elaboración de los Planes Municipales de Vivienda y Suelo, que deben determinar la proporción de los distintos regímenes de viviendas protegidas para dar satisfacción a las necesidades concretas detectadas entre sus vecinos.

En este contexto destaca el también antes citado Decreto 43/2008, de 12 de febrero, sobre condiciones de implantación y funcionamiento de campos de golf. La norma, cuya aprobación colea desde el año 2000, nace con el ob- 
jetivo de evitar la proliferación desmedida de núcleos urbanos en suelo no urbanizable alrededor de estas instalaciones y minimizar el impacto medioambiental de las mismas. A tal efecto, el Decreto exige que la implantación de un campo de golf esté expresamente prevista en la planificación urbanística o territorial correspondiente, lo que fue visto por el sector como una suerte de paralización o de moratoria a estos proyectos (aliviada para los que sean declarados "de interés turístico" -como vimos- por la Ley 1/2008, de 27 de noviembre, que resultó de la tramitación parlamentaria del Decreto-Ley $1 / 2008)$. Asimismo exige que se trate de una actuación aislada que no induzca a la formación de nuevos asentamientos en el caso de que el campo de golf se implante en suelo no urbanizable y asegurando, en el caso de suelo urbano o urbanizable, la unicidad e independencia del correspondiente sector respecto de los residenciales. Por otra parte, dado el gran consumo de agua que requieren estas instalaciones, se establece la preceptiva autorización del organismo de cuenca bajo las condiciones que establezca el plan hidrológico correspondiente, así como la obligación de elaborar un plan de conservación.

En materia de ayuda social y ayuda a las familias, es de resaltar el Decreto 64/2008, de 26 de febrero, que modifica de nuevo el Decreto 137/2002, de 30 de abril, de apoyo a las familias andaluzas con la finalidad de poner en marcha el plan de acceso universal al servicio público de guarderías. Por su parte, el Decreto 415/2008, de 22 de julio adopta una medida pionera en España que ya estaba prevista en el Plan de Apoyo a las Familias Andaluzas: garantizar a la población infantil menor de un año el derecho a la prestación farmacéutica gratuita. Actualmente, los niños menores de un año (en torno a 95.000), abonan -al igual que el resto de la población- entre el 40 y el $10 \%$ del precio de venta de los fármacos, porcentaje que a partir de ahora será asumido íntegramente por la Administración sanitaria con un coste anual previsto de 4,5 millones de euros.

Siguiendo con las cuestiones sociales también es de resaltar el Acuerdo del Consejo de Gobierno de 14 de octubre de 2008, que aprueba el I Plan de Acción Integral para las Mujeres con Discapacidad 2008-2013 que contempla una serie de ayudas para contrarrestar la situación de discriminación que sufre este colectivo, integrado en Andalucía por más de 400.000 personas (el $58 \%$ de la población total con discapacidad). Este Plan se complementa con el Plan de empleabilidad para las personas con discapacidad, de ahí que en el área de igualdad en el empleo se remita a este otro Plan, coincidentes en el período de ejecución.

En materia de dependencia hay que dejar constancia del Acuerdo del Consejo de Gobierno de 25 de noviembre por el que se establecen los crite- 
rios de distribución de los créditos entre Ayuntamientos con población superior a 20.000 habitantes y Diputaciones Provinciales al objeto de financiar la atención a las personas en situación de dependencia.

En lo referente a ayudas de finalidad regional y en favor de las pequeñas y medianas empresa se recordará que Andalucía es una de las regiones que puede acogerse a la excepción del artículo 87.3.a) del Tratado para el período 2007-2013 (por autorizarlo así la Comisión Europea mediante Decisión de 20 de diciembre de 2006). Siguiendo las previsiones del Derecho Comunitario europeo, el programa de ayudas de finalidad regional y en favor de las pequeñas y medianas empresas a conceder por la Administración de la Junta de Andalucía se remitió a la Comisión Europea y se registró como Ayuda N 598/2006. A la espera de que recayese una Decisión favorable sobre el mismo por parte de la Comisión, el Gobierno andaluz aprobó el Decreto 21/2007, de 30 de enero, que estableció el marco regulador de las ayudas de finalidad regional y en favor de las pymes para el periodo 2007-2009. Mediante Decisión de 21 de mayo de 2008, la Comisión dio luz verde al régimen de ayudas del Decreto 21/2007, aunque solicitó información adicional sobre algunos extremos y la introducción de modificaciones en el mismo. Las modificaciones que habían de hacerse a resultas de este periodo de comunicación eran de calado, lo que justifica más que la reforma del anterior Decreto 21/2007, su derogación y sustitución por un nuevo texto: el Decreto Decreto 394/2008, de 24 de junio. Asimismo debe consignarse que aunque la Decisión del régimen 598/2006 autorizó las ayudas hasta el 31 de diciembre de 2009, la Junta de Andalucía ha solicitado una ampliación de las mismas hasta el 31 de diciembre de 2013.

El Decreto 400/2008, de 8 de julio, aprueba marco regulador de las ayudas de Investigación y Desarrollo Tecnológico e Innovación concedidas a empresas. La norma comprende las ayudas concedidas directamente por la Administración autonómica como las que ésta gestiona procedentes de fondos europeos para apoyar la realización de proyectos empresariales de I+D y para estudios de viabilidad técnica previos a las actividades de investigación. El Decreto es uno de los pilares importantes de la política andaluza de fomento de I+D+i en el marco del Plan de Innovación y Modernización de Andalucía 2005-2010, aprobado por Acuerdo del Consejo de Gobierno el 7 de junio de 2005, en el que también se inserta el Plan Andaluz de Investigación, Desarrollo e Innovación (PAIDI 2007-2013), aprobado por Decreto 86/2007, de 27 de marzo. El nuevo marco recoge modalidades de incentivos dirigidas a la obtención y validación de patentes y otros derechos de propiedad industrial; fomento de empresas jóvenes e innovadoras; innovación en procesos y organización en acti- 
vidades de servicios; asesoramiento y fomento a la innovación; préstamo, en régimen de comisión de servicios y a favor de las pymes, de personal altamente cualificado procedente de organismos de investigación sin ánimo de lucro o grandes empresas, y, finalmente, constitución, ampliación y animación de agrupaciones innovadoras.

Por otra parte, el hecho normativo más destacado para el llamado tercer sector ha sido el Decreto 32/2008, de 5 de febrero, que aprueba el Reglamento de Fundaciones en desarrollo de la Ley 10/2005, de 31 de mayo. Su finalidad principal es establecer un mayor control en el régimen económico de las Fundaciones, especialmente en lo referente a la disposición y enajenación de su patrimonio, exigiendo la autorización de la Administración autonómica para la venta de bienes cuyo valor supere el $20 \%$ del activo de la entidad. Además, la norma desarrolla los supuestos recogidos en la Ley sobre el sometimiento de las fundaciones a auditorías externas en sus cuentas anuales, entre ellos que su patrimonio o ingresos superen los 2,4 millones de euros y que el número de trabajadores empleados durante el ejercicio sea superior a 30 . En el caso de las Fundaciones del sector público se establece que la realización de la auditoría externa corresponda a la Intervención General de la Junta de Andalucía.

Finalmente, en materia educativa son muchas las disposiciones que han desarrollado las previsiones de la Ley 17/2007, de 10 de diciembre, de Educación de Andalucía. Destaca, en primer lugar, el Decreto 416/2008, de 22 de julio, por el que se ordenan las enseñanzas correspondientes al Bachillerato en Andalucía de conformidad con las bases estatales de la Ley Orgánica de Educación de 2006 y el Real Decreto de enseñanzas mínimas de 2007. El Decreto andaluz organiza las enseñanzas de Bachillerato en tres modalidades, una menos que hasta ahora, al fundirse en "Ciencias y Tecnología" los anteriores Bachillerato Tecnológico y de Ciencias de la Naturaleza y de la Salud, manteniéndose los de "Artes y Humanidades" y "Ciencias Sociales". De acuerdo con la regulación estatal, se introduce la nueva asignatura "Ciencias para el Mundo Contemporáneo" en primer curso, y "Filosofía" pasa a denominarse "Filosofía y Ciudadanía". Ambas se cursarán con carácter obligatorio en las tres modalidades de Bachillerato. Asimismo se establece la obligatoriedad de cursar la segunda lengua extranjera en primero. En segundo todos los centros deberán ofertarla, aunque será de libre elección para los alumnos. En el bloque de materias optativas, cuya regulación corresponde en exclusiva a la Comunidad Autónoma, se implanta la nueva asignatura, "Proyecto Integrado", que completará la formación del alumnado en aspectos científicos relacionados con la modalidad que curse, tanto en primero como en segundo curso. 
Asimismo, serán de nueva creación y de oferta obligatoria en segundo las materias de "Tecnologías de la Información" y "Comunicación" para todas las modalidades; e "Historia de la Música y de la Danza" para los Bachillerato de "Arte y Humanidades" y de "Ciencias Sociales". Uno de los aspectos más polémicos de esta disposición es que -en línea con lo que viene haciendo la legislación educativa para contrarrestar el fracaso- flexibiliza aún más la optatividad y, sobre todo, el régimen de superación de los cursos académicos.

Por su parte, el Decreto 436/2998, de 2 de septiembre, regula la organización de las enseñanzas de formación profesional inicial que forman parte del sistema educativo en la Comunidad Autónoma, establece modalidades en la oferta de las mismas y determina las características fundamentales que habrá de tener el currículo de las enseñanzas correspondientes a cada uno de los títulos de formación profesional. La norma desarrolla la legislación básica estatal y sienta las premisas para poder adaptar el catálogo de títulos a las necesidades del mercado, así como para ampliar y facilitar las vías de acceso a estos estudios mediante modalidades no presenciales. Con el mismo objetivo de facilitar al máximo el acceso a la FP, se recoge la posibilidad de realizar pruebas dirigidas al alumnado que no tiene el título exigido (Graduado en Educación Secundaria Obligatoria en el caso del Grado Medio y Bachillerato en el de Grado Superior). Para favorecer la conexión de la FP con el ámbito laboral, el Decreto establece la inclusión de módulos de formación en centros de trabajo para todos los ciclos y la ampliación de los programas de prácticas en la Unión Europea.

El Decreto 428/2008, de 29 de julio, adapta a la legislación básica estatal las enseñanzas de Educación Infantil en Andalucía. La norma establece las bases para su universalización progresiva en todo el tramo de 0 a 6 años incrementando progresivamente la oferta de plazas en centros financiados por la Junta que impartan exclusivamente el primer ciclo, con un horario ininterrumpido de 7.30 a 20.00 de lunes a viernes, durante once meses. Con el fin de universalizar la Educación Infantil, la Administración autonómica ofertará durante los próximos cuatro años un total de 100.000 plazas de primer ciclo y, de acuerdo con el Decreto, seguirá incrementando esta cantidad hasta cubrir toda la demanda en la siguiente legislatura. Las familias colaborarán en la financiación de estas plazas según el nivel de ingresos económicos, mientras que, en el segundo ciclo (de 3 a 6 años), la gratuidad está garantizada desde el curso 2007-2008, tal y como recoge el nuevo Estatuto de Autonomía.

Asimismo es de tener en cuenta el Decreto 435/2998, de 2 de septiembre, por el que se aprueban los Estatutos de la Agencia Andaluza de Evaluación 
Educativa, organismo previsto en la Ley 17/2007 de Educación de Andalucía para evaluar y acreditar la labor del personal docente y el rendimiento del alumnado.

\section{CONFLICTIVIDAD}

Las controversias planteadas ante el Tribunal Constitucional en el año 2008 fueron singularmente escasas, reduciéndose a dos, ambas promovidas contra Leyes andaluzas:

- Recurso de inconstitucionalidad núm. 321-2008, admitido a trámite por el Pleno del Tribunal Constitucional mediante Providencia de 12 de febrero de 2008, promovido por más de cincuenta Diputados del Grupo Parlamentario Popular en el Congreso de los Diputados contra los arts. 13, 33.2; 40.1.a), inciso primero del último párrafo; 41.1.c), párrafo segundo y 47.1 y 3 de la Ley 22/2007, de 18 de diciembre, de Farmacia de Andalucía (BOJA núm. 46, de 6 de marzo).

- Recurso de inconstitucionalidad núm. 7258-2008, admitido a trámite por el Pleno del Tribunal Constitucional mediante Providencia de 7 de octubre 2008, promovido por el Presidente del Gobierno contra los arts. 4.b), 16.2 y 3 y 20.3 de la Ley de Andalucía 21/2007, de 18 de diciembre, de Régimen Jurídico y Económico de los Puertos de Andalucía, invocando el artículo 161.2 de la Constitución, lo que produce la suspensión de la vigencia y aplicación de los preceptos impugnados (BOJA núm. 213, de 27 de octubre). Con ello, queda suspendida la facultad de la Junta de Andalucía para autorizar las ocupaciones y utilizaciones del dominio público portuario destinadas a uso hotelero y para compatibilizar el uso portuario con actividades de tipo cultural, deportivo, educativo o ferial que, en cada caso, prevea el Plan de uso de los espacios portuarios.

Son de de destacar dos pronunciamientos del Tribunal Constitucional que resuelven recursos de inconstitucionalidad planteados por la Junta de Andalucía y que, pese a ser de finales de 2007, fueron publicados en el BOE en el mes de enero. En primer lugar la STC 248/2007, de 13 de diciembre de 2007 (Ponente Exmo. Sr. D. Manuel Aragón Reyes), por la que se resuelve el recurso de inconstitucionalidad interpuesto por el Consejo de Gobierno de la Junta de Andalucía contra el artículo 76 y las cuantías fijadas en la sección 32 de la Ley 52/2002, de 30 de diciembre, de presupuestos generales del Estado para 2003. El recurso se interpuso por el desacuerdo con la participa- 
ción de la Comunidad Autónoma en los ingresos del Estado mediante el fondo de suficiencia. La sentencia, que desestima el recurso, argumenta sobre los principios de autonomía y suficiencia financiera y cuenta con dos Votos particulares concurrentes suscritos, respectivamente, por los Exmos. Sres. Conde Martín de Hijas y Rodríguez-Zapata Pérez. En segundo lugar destaca la STC 259/2007, de 19 de diciembre de 2007 (Ponente Exmo. Sr. D. Vicente Conde Martín de Hijas), que resuelve el recurso de inconstitucionalidad interpuesto por la Junta de Andalucía contra la Ley Orgánica 8/2000, de 22 de diciembre, de reforma de la Ley Orgánica 4/2000, de 11 de enero, sobre derechos y libertades de los extranjeros en España y su integración social. Se impugnaban en dicho recurso diversos preceptos de la citada Ley Orgánica relativos a los derechos de reunión, manifestación, asociación, sindicación, huelga y tutela judicial cautelar que se entendían restringidos por la reforma del régimen de extranjería. La sentencia declara la parcial desaparición sobrevenida del objeto procesal, puesto que la STC 236/2007, de 7 de noviembre, ya apreció la inconstitucionalidad de algunos de los preceptos cuestionados por este recurso, aunque estima parcialmente el recurso por apreciar aquí la inconstitucionalidad de otros tres preceptos de dicha Ley. Al igual que hiciera respecto de la STC 236/2007, el Exmo. Sr. Conde, formula un voto particular al que se adhieren los Exmos. Sres. Rodríguez-Zapata y García-Calvo.

Finalmente ha de consignarse que el proverbial colapso que sufre la jurisdicción de lo contencioso-administrativo en Andalucía, reiteradamente denunciado por jueces, fiscales y señalado por las memorias del CGPJ, ha sido condenado por el Tribunal Constitucional en su STC 93/2008, de 21 de julio, que ampara a un ciudadano marroquí en su derecho a un proceso sin dilaciones indebidas a raíz de que un Juzgado de lo Contencioso-Administrativo de Málaga señalase el juicio contra la denegación de la autorización de residencia a dos años y medio vista desde la interposición del recurso.

\section{ACTIVIDAD DE OTRAS INSTITUCIONES ESTATUTARIAS}

\section{Cámara de Cuentas}

La actividad institucional de la Cámara durante el ejercicio ha quedado marcada por la paralización del proceso de renovación de cuatro de los siete cargos directivos de la Cámara que tenía que producirse en 2008 -incluyendo al Consejero Mayor-, y que, pese a su carácter inconcuso, requiere una mayoría parlamentaria de tres quintos que no parece pronta a formarse. 
Dentro de la actividad fiscalizadora del órgano, se han aprobado 20 Informes relativos a la Junta de Andalucía y el sector público andaluz, fundamentalmente centrados en empresas públicas y Universidades; y 17 sobre Corporaciones Locales, la mayoría relativos a distintos servicios y empresas locales o a problemas urbanísticos específicos. Especialmente destacables nos parecen los Informes relativos a los gastos electorales de las elecciones al Parlamento (BOJA núm. 218, de 3 de noviembre) y el de Fiscalización de la Cuenta General, Contratación Administrativa y Fondos de Compensación Interterritorial (BOJA núm. 171, de 28 de agosto). Asimismo resulta de interés el Informe sobre seguimiento de las recomendaciones incluidas en el informe de fiscalización de la gestión de la recaudación ejecutiva en la Comunidad Autónoma de Andalucía (pendiente de publicar en el BOJA) y, de los relativos al sector local, el Informe anual del sector público de las Corporaciones Locales (BOJA núm. 176, de 4 de septiembre).

\section{Defensor del Pueblo Andaluz}

El Informe Anual correspondiente a la gestión realizada durante 2008 fue presentado dentro del primer trimestre del ejercicio de 2009. Los datos revelan una moderada tendencia al incremento del número de quejas presentadas: 5.672 durante 2008 , lo que supone un 2,86 por ciento más que el año anterior. Las reclamaciones versaron sobre personal del sector público (904), educación (680), salud (492), medio ambiente (490), prisiones (356), menores (300) o Dependencia y Servicios Sociales (300).

La Institución ha insistido en la realización de Informes especiales como herramienta relevante en el análisis y la tutela de situaciones sociales merecedoras de singular atención. Durante 2008, se pusieron a la disposición del Parlamento y del conjunto de la sociedad los trabajos sobre "Lugares de custodia de personas detenidas: depósitos municipales y otros calabozos policiales", así como el Informe Especial sobre "Universidades y Discapacidad". Como en años anteriores, la Institución, en su calidad del Defensor del Menor de Andalucía, entregó su Informe Anual del Menor en el mes de Junio.

\section{Consejo Consultivo de Andalucía}

Han sido solicitados al Consejo 808 dictámenes, cifra que marca un máximo histórico. Fueron admitidos a trámite 793. El número de dictámenes emitidos ha sido de 771, la cifra más alta desde la creación del Consejo en 1994. De entre ellos, el número de dictámenes favorables ha sido de 634, los desfavorables ascendieron a 84; y 53 expedientes fueron devueltos. De los dic- 
támenes emitidos, 243 corresponden a solicitudes formuladas por entidades locales, o sea un $32 \%$, porcentaje similar al del año anterior.

El desglose por asuntos principales es el siguiente: un dictamen sobre Anteproyectos de Ley y 57 Proyectos de disposiciones reglamentarias. Han sido 9 las consultas facultativas. En cuanto a los asuntos administrativos ordinarios han sido 102 los dictámenes relativos a revisiones de oficio (13\% sobre el total de los emitidos); 85 (11\%) sobre contratación; 65 (8\%) de modificaciones de Planes urbanísticos afectantes a zonas verdes, espacios libres, dotaciones y equipamientos; 7 se han emitido sobre recursos de revisión y 1 sobre transacción. Es singularmente alto el número de dictámenes emitidos sobre responsabilidad patrimonial de la Administración, 444 (58\%), correspondiendo 344 de ellos a asuntos procedentes de la Administración autonómica, 97 de entidades locales y 3 de universidades.

En cuanto al deber de las Administraciones de comunicar al Consejo el sentido de las resoluciones adoptadas tras la recepción de los dictámenes, el número de estas comunicaciones fue de 489, de ellas 452 resoluciones fueron dictadas "de conformidad" con el dictamen, y que fueron 37 aquellas en que el Consejo fue sólo "oído".

\section{Consejo Audiovisual de Andalucía}

Sin duda, el hecho más destacado en la vida de esta Institución durante el pasado ejercicio fue la dimisión en el mes de mayo, tras la presentación de la Memoria anual de 2007 ante el Parlamento y justo en el ecuador de su mandato, del primer Presidente del Consejo Audiovisual, D. Manuel Ángel Vázquez Medel. Según las propias manifestaciones del dimisionario ante los medios de comunicación, el hecho obedecía a la agudización de los enfrentamientos internos en el seno del Consejo y a una "instrumentalización partidista" del mismo de la que responsabilizó a sus Consejeros. A propuesta mayoritaria del Pleno del organismo, el Consejo de Gobierno designó a D. Juan Montabes Pereira, Catedrático de Ciencia Política y de la Administración de la Universidad de Granada, como nuevo Presidente del Consejo Audiovisual mediante Decreto 410/2008, de 15 de julio.

Durante el ejercicio, el Pleno adoptó 33 Resoluciones (muy sonada fue la que denunció algunas actuaciones de Canal Sur durante la campaña electoral, ratificando los pronunciamientos efectuados en este sentido por la Junta Electoral de Andalucía), dos recomendaciones (una sobre el tratamiento de la información electoral y otra sobre violencia en el deporte) y sólo un Informe, 
adoptado a principios de año en relación con la emisión de contenidos atentatorios para los menores fuera de la franja horaria de protección legalmente establecida. Muy de reseñar es la decidida acción emprendida por el Consejo en este terreno, que ya iniciara en septiembre de 2007 mediante una serie de recomendaciones dirigidas a los operadores infractores. Es de celebrar que en abril de 2008 se comenzaran a instruir los primeros expedientes sancionadores y en septiembre se impusieran las primeras sanciones. Otras líneas de actuación en las que el Consejo ha avanzado son la denuncia de la discriminación por razón de género y el empleo de estereotipos discriminatorios en la publicidad. 